\title{
ORIGINAL ARTICLE Urologic health condition of spinal cord-injured patients living in Turkey
}

\author{
B Cetinel ${ }^{1}$, B Onal ${ }^{1}$, FA Turegun ${ }^{1}$ and S Erdogan ${ }^{2}$
}

\begin{abstract}
Objectives: To determine the urologic health condition of spinal cord-injured (SCI) patients living in Turkey, and to analyze the relationship between the prevalence of urologic health condition parameters and the patient's characteristics.

Methods: Telephone call survey was conducted with a structured questionnaire among all members of Turkish Society of Spinal Cord Injured Patients.

Results: Data were obtained from 300 patients. Mean age was 42 years with a male/female ratio of 2.3 , while the most common cause of injury was transport (35.3\%). Although $70 \%$ were aware of potential kidney and bladder problems after injury $>60 \%$ of the patients were not under regular urologic follow-up. Secondary health problems experienced as being most important was urination problems (50\%). Of the patients $72.7 \%$ ( $83 \%$ in females vs $68 \%$ in males) had urinary incontinence (UI) during last 3 months, and $64.3 \%$ used clean intermittent catheterization (CIC) $(68 \%$ in males vs $56 \%$ in females), while $73 \%, 57 \%$ and $26 \%$ of incontinent patients used diaper/pad, medication and condom catheter, respectively, and the use of CIC decreased with time. Surgical procedures on urinary tract were performed in $22.6 \%$ of the patients; stone surgeries were the most frequent ones.

Conclusion: This study demonstrated that the UI rate was high among SCl patients, and more common in females with fairly good proportion of patients using incontinence medication. Main bladder management method was $\mathrm{CIC}$ and more prevalent in males, although the use of $\mathrm{CIC}$ decreased with time. Urinary stone surgery was the leading surgical procedure.
\end{abstract}

Spinal Cord (2014) 52, 302-306; doi:10.1038/sc.2013.173; published online 21 January 2014

Keywords: urinary incontinence; voiding dysfunction; epidemiology; urology; spinal cord injury

\section{INTRODUCTION}

Prevalence of spinal cord injury (SCI) was reported to be in the range of 223-755 per million inhabitants in a review article. ${ }^{1}$ Prevalence data came from the five studies of developed countries. This review article found no data on Asia, Africa, South-America, and consequently could not produce a worldwide SCI prevalence estimate. The same review article found the reported incidence of SCI to lie between 10.4 and 83 per million inhabitants per year. ${ }^{1}$ This review included three incidence studies from Turkey, which reported incidence of SCI in Turkey to be between 12.7 and 21 per million inhabitants per year. ${ }^{2-4}$ Most of the patients with SCI will develop neurogenic lower urinary tract dysfunction. ${ }^{5}$ There is no epidemiologic data concerning the urologic health condition of SCI patients living in Turkey, and their awareness of the urologic complications after they discharge from the rehabilitation clinics. A postal survey among the members of the Dutch Association of Patients with SCI demonstrated that patients with SCI living in the community experienced many health problems, and the occurrence of these problems did not diminish with increasing time after injury. The authors of this study emphasized the need for follow-up care in patients with SCI. ${ }^{6}$ Authors also stated that life-long care for persons with SCI was still underdeveloped in Netherlands since after discharge from in-patient rehabilitation, care for SCI patients was transferred from the rehabilitation center to primary health care in Netherlands. ${ }^{6}$ The situation is not better in Turkey than that in Netherlands. Care for patients with SCI in Turkey after discharge from rehabilitation centers also is transferred to primary health-care professionals who do not see SCI patients often in their clinical practice. Additionally, rehabilitation centers well equipped with multidisciplinary approach for patients with SCI are not common in Turkey. ${ }^{7}$ Therefore, in this study we aimed to determine the urologic health condition of SCI patients living in Turkey and their awareness of potential kidney and bladder problems after the injury. This telephone survey study also aimed to identify the secondary health problems experienced as most important, and to study the relationships between the occurrence of urinary incontinence (UI), bladder management methods and patient/injury characteristics. Hopefully, the results will present some important data about the urologic health condition of these patients to health-care authorities, societies of SCI patients and professionals of urologic rehabilitation.

\section{MATERIALS AND METHODS}

\section{Preparation of the questionnaire}

Structured questionnaire was prepared on the basis of the 'Lower Urinary Tract Function Basic SCI Data Set' and the 'International SCI Core Data Set. ${ }^{8,9}$ Therefore, the first part of the questionnaire included information on date of birth and injury, gender, the cause of spinal cord lesion and neurologic status. A question to identify the three most important secondary health problems experienced by the patient was added to the first part. On the other hand, the second part consisted of questions relating to the urologic health condition of the patient such as awareness of the emptying need, way of bladder emptying, the presence of UI within the last 3 months, the use of collecting appliances for

${ }^{1}$ Department of Urology, University of Istanbul Cerrahpasa School of Medicine, Istanbul, Turkey and ${ }^{2}$ Department of Public Health, University of Istanbul Cerrahpasa School of Medicine, Istanbul, Turkey

Correspondence: Professor B Cetinel, Uroloji Anabilim Dali, Cerrahpasa Tip Fakultesi, Istanbul 34098, Turkey.

E-mail: bulent.cetinel@hotmail.com

Received 11 September 2013; revised 11 December 2013; accepted 23 December 2013; published online 21 January 2014 
UI, the use of drugs for the urinary tract within the last year and the presence of surgical procedures on the urinary tract. Additional questions regarding the use of urinary tract imaging, urodynamic studies, urine culture test, consistent urinary follow-up, and the patient's awareness of potential kidney and bladder problems were added to this part.

\section{Data collection}

All members of Turkish Society of Spinal Cord Injured Patients were called for an interview with the prepared questionnaire.

Telephone call interviews by using this questionnaire were performed by one person who was an SCI patient herself and also a board member of Turkish Society of Spinal Cord Injured Patients.

\section{Statistical analysis}

Statistical analysis was done by SPSS, version 13.0 (Istanbul University, Istanbul, Turkey). Comparisons were done using Mann-Whitney and chi-square testing where appropriate, and statistical significance was defined as $P<0.05$.

\section{RESULTS}

Totally, 459 persons with SCI were called. It was not possible to reach 94 patients, 57 patients declined to participate, and

\section{Table 1 Patient and injury characteristics}

\begin{tabular}{|c|c|}
\hline $\begin{array}{l}\text { Patient characteristics } \\
\text { No. of patients }\end{array}$ & 300 \\
\hline Mean age (years) & $42(14-69)$ \\
\hline \multicolumn{2}{|l|}{ Gender } \\
\hline Female & $90(30 \%)$ \\
\hline Male & $210(70 \%)$ \\
\hline Mean time of injury (years) & $14(1-51)$ \\
\hline $0-10$ & 123 \\
\hline $11-20$ & 122 \\
\hline$>20$ & 55 \\
\hline \multicolumn{2}{|l|}{ Etiology of injury } \\
\hline Transport & $106(35.3 \%)$ \\
\hline Fall & $84(28 \%)$ \\
\hline Assault & $32(10.7 \%)$ \\
\hline Non-traumatic spinal cord dysfunction & $28(9.3 \%)$ \\
\hline Diving in shallow water & $12(4 \%)$ \\
\hline Sports & $1(0.3 \%)$ \\
\hline Other injury & $29(9.7 \%)$ \\
\hline Unknown & $8(2.7 \%)$ \\
\hline \multicolumn{2}{|l|}{ Type of injury } \\
\hline Paraplegia & $246(82.0 \%)$ \\
\hline Quadriplegia & $41(13.7 \%)$ \\
\hline Unknown & $13(4.3 \%)$ \\
\hline \multicolumn{2}{|c|}{ Awareness of potential kidney and bladder problems after injury } \\
\hline Yes & $212(70.7)$ \\
\hline No & $88(29.3)$ \\
\hline \multicolumn{2}{|l|}{ Source of this awareness } \\
\hline Doctors/Professionals in rehabilitation centers & $149(71.3)$ \\
\hline Internet/Written and visual media & $14(6.7)$ \\
\hline Society of Spinal Cord Injured Patients & $15(7.2)$ \\
\hline Friends & $9(4.3)$ \\
\hline Mixed & $2(0.9)$ \\
\hline Others & $20(9.6)$ \\
\hline No answer & $3(1.4)$ \\
\hline
\end{tabular}

8 patients had died. Consequently, the final sample consisted of 300 persons $(65.3 \%)$.

Table 1 shows the patient and injury characteristics. Mean age of the patients was 42, varying between 14 and 69. Majority of the patients were males (70\%). Paraplegics constituted the $82 \%$ of the whole patient population while $13.7 \%$ were quadriplegics. Time after injury varied between 1 and 51 years, while 123 patients were in $0-10$ years interval, 122 in $11-20$ and 55 in longer than 20 years. The most common causes of injury were transport (car accidents) (35.3\%), fall (28\%) and assault (10.7\%).

Seventy percent of the patients were aware of potential kidney and bladder problems after injury, and the majority of the patients (70\%) stated that the information for this awareness came from doctors and professionals in rehabilitation centers. Society of Spinal Cord Injured Patients supplied this information in only $7.2 \%$ of the patients (Table 1).

Health problems experienced as being most important were presented in Table 2 . The first three rank order of secondary health problems experienced as most important was urination problems (50\%), bowel problems (17.3\%) and extremity muscle spasm (8\%). Of the whole patient population, $75 \%, 63 \%$ and $32 \%$ of the patients indicated urination, bowel and extremity spasm problems as being three top most important health problems, respectively.

The frequency of secondary voiding dysfunction problems was presented in Table 3. Sensation of urination problems was present in $69 \%$ of the patients, while $72.7 \%$ of the patients declared that they experienced urinary leakage during last 3 months. Only $16.3 \%$ of the patients declared no problem in urination, while $64.3 \%$ used clean intermittent catheterization (CIC) and $8 \%$ indwelling catheters for emptying their bladders. Voiding by valsalva maneuver was reported by $7.3 \%$ of the patients.

Relationship between the status of urologic problems and patient characteristics such as age, gender and type of injury was shown in Table 4. The mean age of the respondents (39.9 (14-62) years) who declared that they were using CIC was significantly smaller than the mean age of the respondents who were not performing CIC (45.7

Table 2 Health problems experienced as being most important

\begin{tabular}{|c|c|c|}
\hline Secondary impairment & $\begin{array}{l}\text { Number of } \\
\text { respondents } \\
\text { who stated as } \\
\text { most important } \\
\text { problem, n (\%) }\end{array}$ & $\begin{array}{c}\text { Number of } \\
\text { respondents } \\
\text { who stated as most } \\
\text { important top three } \\
\text { problems, n (\%) }\end{array}$ \\
\hline Urination problems & $150(50)$ & $224(75)$ \\
\hline Bowel problems & $52(17.3)$ & $189(63)$ \\
\hline Extremity muscle spasm & $24(8)$ & $95(32)$ \\
\hline Pain & $9(3)$ & $61(20.3)$ \\
\hline Edema & $2(7)$ & $10(3.3)$ \\
\hline Pressure wound & $18(6)$ & $76(25.3)$ \\
\hline Excessively sweating & $7(2.3)$ & $22(7.3)$ \\
\hline $\begin{array}{l}\text { Contractures (decreased joint mobility } \\
\text { due to reduction in muscle length) }\end{array}$ & $7(2.3)$ & $29(9.6)$ \\
\hline $\begin{array}{l}\text { Breathing/respiratory tract (for example, } \\
\text { shortness of breath and infection of } \\
\text { respiratory tract) }\end{array}$ & $3(1)$ & $17(5.6)$ \\
\hline Increasing weight & $4(1.3)$ & $24(8)$ \\
\hline Limitations of daily living activities & $14(4.7)$ & $95(31.6)$ \\
\hline Sexual problems & $10(3.3)$ & $42(14)$ \\
\hline
\end{tabular}


(25-69) years). The CIC rate was significantly decreasing as the time after injury increased (Figure 1). UI was significantly more common in females ( 83 vs $68 \%$ ) while the use of CIC was more prevalent in males ( 68 vs 56\%), and the patients using CIC were younger than the patients who do not (39.9 vs 45.7 ). No other significant relationship was found between the status of the urologic problems and patient/ injury characteristics.

Table 5 presents the treatment and follow-up characteristics. Of the patients $31 \%$ did not use any collecting appliances, while $26 \%$ and

Table 3 Secondary voiding dysfunction problems

\begin{tabular}{lc}
\hline & $\mathrm{n}(\%)$ \\
\hline $\begin{array}{l}\text { Existing of urinary problem before injury } \\
\text { Yes }\end{array}$ & $14(4.7)$ \\
No & $284(94.7)$ \\
Unknown & $2(0.7)$ \\
& \\
Sensation of urination after injury & \\
Yes & $86(28.7)$ \\
No & $113(37.7)$ \\
Yes, but not like before injury & $94(31.3)$ \\
Unknown & $7(2.3)$ \\
& \\
Emptying urine & \\
Normal & $49(16.3)$ \\
Valsalva & $22(7.3)$ \\
CIC & $193(64.3)$ \\
Self-catheterization & $142(74)$ \\
By relatives & $50(26)$ \\
Indwelling catheter & $24(8)$ \\
Urethral catheter & $22(95.7)$ \\
Cystofix & $1(4.3)$ \\
Urostomy & $2(0.7)$ \\
Others & $10(3.3)$ \\
Urinary leakage experienced during last 3 months & \\
No & \\
Frequently & \\
Rare & $82(27.3)$ \\
Very rare & $93(31)$ \\
& $81(27)$ \\
A & $44(14.7)$ \\
\hline
\end{tabular}

Abbreviation: CIC, clean intermittent catheterization.
$73 \%$ of the incontinent patients used condom catheter and diaper/ pad, respectively. Of the patients 38\% did not use any medication or drugs for urinary problems during the last year, while urinary leakage $(42 \%)$ and urinary infection $(22 \%)$ were the most frequent reasons for drug use. Surgical procedures on urinary tract were performed in $22.6 \%$ of the patients, stone surgeries being the most frequent ones $(17.3 \%)$ while augmentation cystoplasty $(0.7 \%)$, intravesical botulinum toxin application $(0.3 \%)$ and artificial urinary sphincter (AUS) implantation $(0.3 \%)$ were rare. Urinary tract imaging, urodynamic studies and urine culture studies were performed in 67.7, 76 and $85 \%$ of the patients, respectively, after injury. The percentage of the patients who had regular follow-up for urinary system after injury was $38.3 \%$.

\section{DISCUSSION}

In the present study, $72.7 \%$ of SCI patients had UI during the last 3 months while the frequent UI was found to be $31 \%$. Consequently, $42 \%$ of the respondents used medication for UI. A recent epidemiologic follow-up study of SCI patients demonstrated a similar rate of UI (54\%), while only a minority of individuals (19\%) used medication for the treatment of incontinence. ${ }^{10}$ Furthermore, a frequent UI rate $(30 \%)$ in that study was nearly the same as the rate $(31 \%)$ in our study. ${ }^{10}$ In another study, a lower UI rate (38.1) was determined in SCI patients. ${ }^{6}$ In the present study, we found no difference in the frequencies of UI between respondents' characteristics such as age, time of injury and the level of injury. Statistical difference was determined only between the frequency of UI and gender (Table 4). UI was more common in female respondents. One possible explanation could be that in the general community UI rates were found to be higher in middle-aged women than in men due to higher prevalence of stress incontinence and idiopathic detrusor overactivity in middle-aged women. In this regard, our findings were not consistent with the findings of Hansen et al. ${ }^{10}$ who determined a trend across the groups of incontinence with more paraplegics reporting daily incontinence compared with quadriplegics.

The incontinence management methods of the incontinent respondents $(218$ patients) were pad usage $(159 / 218=73 \%)$, medication $(126 / 218=57 \%)$ and condom catheter (men only) $(37 / 143=26 \%)$ in our study, while Hansen et al. ${ }^{10}$ reported these rates to be 37,19 and $36 \%$ respectively. Those authors speculated that limited usage of pharmacotherapy against UI could be because of a reluctant or conservative approach by the health-care professionals or insufficient urological follow-up of these patients. A high rate of UI medication

Table 4 Relationship between the status of urologic problems and patient characteristics such as age, gender and type of injury

\begin{tabular}{|c|c|c|c|c|c|c|}
\hline & $\begin{array}{c}\text { Number of respondents } \\
\text { who experienced urinary } \\
\text { incontinence }\end{array}$ & $\begin{array}{l}\text { Number of respondents } \\
\text { who did not experience } \\
\text { urinary incontinence }\end{array}$ & P-value & $\begin{array}{c}\text { Number of respondents } \\
\text { performing } C I C\end{array}$ & $\begin{array}{c}\text { Number of respondents } \\
\text { who are not performing } \mathrm{CIC}\end{array}$ & $\mathrm{P}$-value \\
\hline Mean age & $42.3(14-68)$ & 41.5 (15-69) & $0.524^{a}$ & $39.9(14-62)$ & $45.7(25-69)$ & $>0.001^{a}$ \\
\hline \multicolumn{7}{|l|}{ Gender, $n(\%)$} \\
\hline Female, 90 (30) & $75(83)$ & $15(17)$ & $0.007^{b}$ & $50(56)$ & $40(44)$ & $0.046^{b}$ \\
\hline Male, 210 (70) & $143(68)$ & $67(32)$ & & $142(68)$ & $68(32)$ & \\
\hline \multicolumn{7}{|l|}{ Type (level) of injury, n (\%) } \\
\hline Paraplegia, 246 (85.7) & $181(73.5)$ & $65(26.5)$ & $0.481^{b}$ & $164(66.6)$ & $82(33.4)$ & $0.189^{b}$ \\
\hline Quadriplegia, 41 (14.3) & $28(68.2)$ & $13(31.8)$ & & $23(56)$ & $18(44)$ & \\
\hline
\end{tabular}

Abbreviation: $\mathrm{CIC}$, clean intermittent catheterization.

aMann-Whitney U-test.

${ }^{\mathrm{b}} \mathrm{Chi}$-square test. 


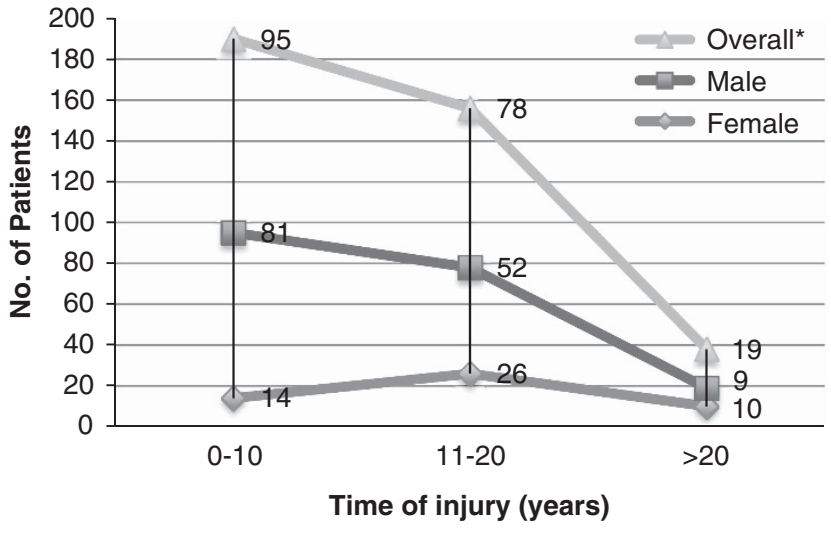

${ }^{*}$ Chi-square, $p>0.001$

Figure 1 The use of $\mathrm{CIC}$ in female and male according to the time of injury.

usage in the present study could be a result of the educational activities of the society of which the survey was performed among the members.

Recent study from United States investigating the actual rates of bladder management methods for SCI patients in clinical practice demonstrated that the use of CIC increased from 12.6\% in 1972-1975 to a peak of $56.2 \%$ in 1991 to 1995 , although only $20 \%$ of patients initially on CIC remained on this form of bladder management at long-term follow-up. ${ }^{11}$ Yavuzer et al. ${ }^{12}$ in a series of 50 SCI patients demonstrated that $52 \%$ of patients on CIC at discharge discontinued this method and reverted to indwelling catheter during follow-up. Dependence on caregivers, severe spasticity interfering with catheterization, incontinence despite anticholinergic agents, and lack of availability of external collective devices for female patients were found to be the main reasons for low compliance with CIC. ${ }^{12}$ The present study demonstrated that $64.3 \%$ of the respondents used CIC, and the rate of CIC was significantly lower in the females compared with the males. Furthermore, the use of CIC decreased with time. Although we did not investigate the reasons for the decline of CIC use with time in this study, same reasons in Yavuzer's study could hold true for this decline. These findings in our study were in good correlation with the findings of those studies. ${ }^{11,12}$ A recent study investigated the effects of different bladder management methods on the quality of life in patients with SCI, and found that the quality of life was notably negatively affected in the group of intermittent catheterization done by an attendant. ${ }^{13}$ The use of indwelling catheter rate was found to be $8 \%$ in the present study. This low rate and high rate of CIC may be the result of the educational activities of the Turkish Society of Spinal Cord Injured Patients, which emphasized that bladder management with indwelling catheter resulted in many urological complications, such as bladder and renal stones, urinary tract infection, erosions and bladder cancer. ${ }^{14-16}$ These educational activities of the society also underlined that CIC was the gold standard for bladder management according to the published guidelines. ${ }^{17,18}$

Of the respondents, $70 \%$ was aware of the potential kidney and bladder problems after SCI. This high rate of awareness correlates well with the high rates of the performance of urinary tract imaging $(67.7 \%)$ and urodynamic studies $(76 \%)$ after the injury. Although respondents stated that the source of this awareness mostly was the doctors and professionals in the rehabilitation centers, and only $7.2 \%$ of the respondents received this information from the society, it was obvious that as being the society's members, SCI patients had the
Table 5 Characteristics of treatment and follow-up

n (\%)

$\begin{array}{lc}\text { Treatment characteristics } & \\ \text { Using any collecting appliances } & \\ \text { No } & 93(31) \\ \text { Condom catheter } & 37(12.3) \\ \text { Pads } & 159(53) \\ \text { Urostomy } & 3(1) \\ \text { Others } & 2(0.7) \\ \text { Mixed } & 6(2) \\ \text { Using medication/drugs for urinary problems during last year } & \\ \text { No } & 115(38.3) \\ \text { Yes, for urinary leakage } & 117(39) \\ \text { Yes, for facilitating of urination } & 2(0.2) \\ \text { Yes, for urinary infection (Antibiotic) } & 57(19) \\ \text { Yes, for both urinary leakage and urinary infection } & 9(3) \\ \text { Undergoing any surgical procedure on urinary tract after injury } & \\ \text { No } & 232(77.3) \\ \text { Cystofix } & 3(1) \\ \text { Bladder stone } & 36(12) \\ \text { Kidney and ureter stone } & 16(5.3) \\ \text { Augmentation } & 2(0.7) \\ \text { Artificial sphincter } & 1(0.3) \\ \text { Botox } & 1(0.3) \\ \text { Urostomy } & 1(0.3) \\ \text { Others } & 8(2.7)\end{array}$

Follow-up characteristics

Urinary tract imaging after injury

No

$97(32.3)$

Yes

$203(67.7)$

Urodynamic studies after injury

No

Yes

Checking with urinary culture after injury

No

Yes

Regular follow-up for urinary system after injury

No

185 (61.7)

Yes

115 (38.3)

49 (42.6)

$57(49.6)$

Every 1 year

$9(7.8)$

Every 2 years

advantage of being directed to rehabilitation centers easily by the society. The findings of high awareness of potential urologic problems and high rates of the performance of urodynamic and imaging studies demonstrate clearly the vital importance of a society for patients with SCI. On the other hand, this high rate of awareness unfortunately did not result in a high rate of regular urologic follow-up of the patients since only $38 \%$ of the patients had regular urologic follow-up. Transportation and monetary problems could account for this relatively low rate of regular urologic follow-up.

The most important problem for the majority of the patients (50\%) was urination problems. This finding was in good correlation with the finding of Bloemen-Vrencken et al. ${ }^{6}$ who demonstrated the most important problem as bladder regulation problem in $51.8 \%$ of the SCI patients.

It was demonstrated that detrusor onabotulinum toxin A injections improved incontinence, urodynamic parameters and quality of life 
in SCI patients with neurogenic detrusor overactivity. ${ }^{19}$ In the present study, fairly good proportion $(57 \%)$ of the incontinent patients used medication for UI, however only $0.4 \%$ of the incontinent patients reported detrusor botulinum toxin A injection treatment. To our knowledge, there is not any epidemiologic study that demonstrates the performance rate of vesical botulinum toxin treatment in SCI patients. The performance rate in our study seems to be extremely low, and this can be explained by the fact that vesical botulinum toxin injection treatment in neurogenic detrusor overactivity is still not reimbursed in Turkey. Although this study is not designed to differentiate the incomplete SCI lesions from the complete ones, no patient in this survey reported transcutaneous electric nerve stimulation or sacral neuromodulation treatment methods that can treat UI in patients with incomplete SCI lesions. Reimbursement problems of transcutaneous electric nerve stimulation treatment and the lack of specialized centers for sacral neuromodulation treatment in our country could account for these results.

AUS implantation rate in incontinent patients of the present study also seems to be very low $(0.4 \%)$. Although AUS implantation is reimbursed in Turkey, it is obvious that evaluation and especially surgical treatment of SCI patients must be done in specialized rehabilitation centers with dedicated and specialized urologic surgeons. Those multidisciplinary rehabilitation centers are lacking in Turkey that may explain the extremely low performance rate of AUS implantation in SCI patients. ${ }^{7}$

Epidemiological studies from Turkey reported the annual incidence of traumatic SCI to be between 16.9 and 21 per million population. ${ }^{2,3}$ In those studies, the most common causes of SCI were reported to be falls, car accidents and assault, which were consistent with the findings of the present study. Our findings regarding the most common causes of SCI also correlate well with the findings of National Spinal Cord Injury Statistical Center in United States which reported these main causes as motor vehicle accidents $(42.1 \%)$ and falls $(26.7 \%) .^{20}$ Majority of the patients were males in the present study with a male/female ratio of 2.3/1. The finding of male preponderance in the present study correlates well with the findings of other studies. ${ }^{1-4}$

There are several limitations to our study. First, the response rate $(65.3 \%)$ was relatively low in our study, possibly caused by the use of a long questionnaire with telephone call interviews. The prevalence of health problems could be overestimated since responses might have mainly come from persons with serious injuries or who are suffering from serious health problems. Second, our study group includes only selected persons who are members of Turkish Society of Spinal Cord Injured Patients. These patients may not represent all patients with SCI since they are more aware of potential urologic problems than those who are not members of the society. Despite these limitations, we believe that our results will provide useful information about the urologic health condition of SCI patients living in Turkey, and their awareness of potential kidney and bladder problems after the injury.

\section{Conclusions}

This study demonstrated that the UI rate was high among SCI patients with fairly good proportion of patients using incontinence medication. UI was more common in females. Main bladder management method was CIC, and more prevalent in males, although the use of CIC decreased with time. The most common surgical procedure was urinary tract stone surgery, while the application of vesical botulinum toxin injection and AUS implantation was rare. Although majority of patients were aware of the potential kidney and bladder problems after SCI, $>60 \%$ of the patients were not under regular urologic follow-up.

\section{DATA ARCHIVING}

There were no data to deposit.

\section{CONFLICT OF INTEREST}

Dr Cetinel's work has been funded by Allergan Inc, Irvine, CA. Telephone and personnel expenses were compensated from this fund.

\section{ACKNOWLEDGEMENTS}

This study was funded by Allergan Inc, Irvine, CA. We would like to thank to Ramazan Bas, the president of Turkish Society of Spinal Cord Injured Patients and also to express our sincere gratitude to Semra Cetinkaya, Nurhan Kaya, Gulsah Bulgur and Begum Kaya for all of their technical and practical assistance during the project.

1 Wyndaele M, Wyndaele J-J. Incidence, prevalence and epidemiology of spina cord injury: what learns a worldwide literature survey? Spinal Cord 2006; 44 523-529.

2 Karamehmetoglu SS, Unal S, Karacan I, Yílmaz H, Togay HS, Ertekin M et al. Traumatic spinal cord injuries in Istanbul, Turkey. An epidemiological study. Paraplegia 1995; 33: 469-471.

3 Karamehmeto ğlu SS, Nas K, Karacan I, Sarac AJ, Koyuncu H, Ataoğlu S et al. Traumatic spinal cord injuries in southeast Turkey: an epidemiological study. Spinal Cord 1997; 35: 531-533.

4 Karacan I, Koyuncu H, Pekel O, Sümbüloglu G, Kirnap M, Dursun H et al. Traumatic spinal cord injuries in Turkey: a nation-wide epidemiological study. Spinal Cord 2000 38: 697-701.

5 Burns AS, Rivas DA, Ditunno JF. The management of neurogenic bladder and sexual dysfunction after spinal cord injury. Spine 2001; 26: S129-S136.

6 Bloemen Vrencken JHA, Post MWM, Hendriks JMS. Health problems of persons with spinal cord injury living in the Netherlands. Disabil Rehabil 2005; 27: 1381-1389.

7 Çetinel B, Önal B. Omurilik Lezyonlarında Nöroürolojik Sorunlar. In: Hancı M and Erhan B (eds), Omurga ve Omurilik Yaralanmaları ISBN 9786058731561, Chapter 52. Intertip Yayinevi Izmir, 2013, pp 447-458.

8 Biering-Sørensen F, Craggs M, Kennelly M, Schick E, Wyndaele JJ. The lower urinary tract function basic spinal cord Injury data set. Spinal Cord 2008; 46: 325-330.

9 DeVivo M, Biering-Sørensen F, Charlifue S, Noonan V, Post M, Stripling T et al. International spinal cord Injury core data set. Spinal Cord 2006; 44: 535-540.

10 Hansen RB, Biering-Sørensen F, Kristensen JK. Urinary incontinence in spinal cord injured individuals 10-45 years after injury. Spinal Cord 2010; 48: 27-33.

11 Cameron AP, Wallner LP, Tate DG, Sarma AV, Rodriguez GM, Clemens JQ et al. Bladder management after spinal cord Injury in the United States 1972 to 2005. J Urol 2010; 184: 213-217.

12 Yavuzer G, Gök H, Tuncer S, Soygür T, Arikan N, Arasil T et al. Compliance with bladder management in spinal cord injury patients. Spinal Cord 2000; 38: 762-765.

13 Akkoç Y, Ersöz M, Yıldız N, Erhan B, Alaca R, Gök H et al. Effects of different bladder management methods on the quality of life in patients with traumatic spinal cord injury. Spinal Cord 2013; 51: 226-231.

14 Esclarin De Ruz A, Garcia Leoni E, Herruzo Cabrera R. Epidemiology and risk factors for urinary tract infection in patients with spinal cord injury. J Urol 2000; 164: 1285.

15 Groah SL, Weitzenkamp DA, Lammertse DP, Whiteneck GG, Lezotte DC, Hamman RF et al. Excess risk of bladder cancer in spinal cord injury: evidence for an association between indwelling catheter use and bladder cancer. Arch Phys Med Rehabil 2002; 83: 346.

16 Weld KJ, Dmochowski RR. Effect of bladder management on urological complications in spinal cord injured patients. J Urol 2000; 163: 768.

17 Pannek J, Stöhrer M, Blok B, Castro-Diaz D, Del Popolo G, Kramer G et al. Guidelines on Neurogenic Lower Urinary Tract Dysfunction. Arnhem, The Netherlands: European Association of Urology (EAU). 2011 Mar. pp 64 [592 references].

18 Abrams P, Agarwal M, Drake M, El-Masri W, Fulford S, Reid S et al. A proposed guideline for the urological management of patients with spinal cord injury. BJU Int 2008; 101: 989 .

19 Chen YC, Kuo HC. The therapeutic effects of repeated detrusor injections between 200 or 300 units of onabotulinumtoxinA in chronic spinal cord Injured patients. Neurourol Urodyn 2013; 33: 129-134.

20 National Spinal Cord Injury Statistical Center. Facts and figures at a glance. 2009 Available at: https://www.nscisc.uab.edu/public_content/facts_figures_2009.aspx (accessed 14 January 2010). 